\title{
The Physiologic Basis and Clinical Applications of Cryotherapy And Thermotherapy for the Pain Practitioner
}

\author{
Scott F. Nadler, DO, FACSM, Kurt Weingand, PhD, DVM, and Roger J. Kruse, MD
}

Cryotherapy and thermotherapy are useful adjuncts for the treatment of musculoskeletal injuries. Clinicians treating these conditions should be aware of current research findings regarding these modalities, because their choice of modality may affect the ultimate outcome of the patient being treated. Through a better understanding of these modalities, clinicians can optimize their present treatment strategies. Although cold and hot treatment modalities both decrease pain and muscle spasm, they have opposite effects on tissue metabolism, blood flow, inflammation, edema, and connective

Musculoskeletal injuries and their treatment are a continual problem for Americans. The American Academy of Orthopaedic Surgeons reports that musculoskeletal injuries and disorders affect one out of every seven Americans and cost more than 215 billion dollars annually (1). Each year in the United States, musculoskeletal injuries cause children to lose more than 21 million days of school and employed workers to lose more than 147 million days of work (1). Topical cold and heat are commonly used to treat injuries of the musculoskeletal system (bone, ligaments, muscles, and tendons). These modalities are useful adjuncts to exercise, medication, and patient education for the comprehensive treatment of many painful musculoskeletal conditions. Although topical hot and cold modalities have been

From New Jersey Medical School, Newark, New Jersey, P\&G Health Sciences Institute, Cincinnati, Ohio, and Sports Care, Toledo, Ohio. Address Correspondence: Scott F. Nadler, DO, FACSM, New Jersey Medical School, 90 Bergen Street, Suite 3100, Newark, New Jersey 07102.

E-mail: sfnadler@cs.com

Funding: There was no external funding in preparation of this manuscript.

Conflict of Interest: None

Acknowledgement: Manuscript received on 5/20/ 04. Revision submitted on 5/25/04. Accepted for publication on $5 / 26 / 04$. tissue extensibility. Cryotherapy decreases these effects while thermotherapy increases them. Continuous low-level cryotherapy and thermotherapy are newer concepts in therapeutic modalities. Both modalities provide significant pain relief with a low side-effect profile. Contrast therapy, which alternates between hot and cold treatment modalities, provides no additional therapeutic benefits compared with cryotherapy or thermotherapy alone. Complications of cryotherapy include nerve damage, frostbite, Raynaud's phenomenon, cold-induced urticaria, and slowed wound healing. With thermotherapy, skin burns may occur, especially in patients with diabetes mellitus, multiple sclerosis, poor circulation, and spinal cord injuries. In individuals with rheumatoid arthritis, deepheating modalities should be used with caution because increased inflammation may occur. Whirlpool and other types of hydrotherapy have caused infections of the skin, urogenital, and pulmonary systems. Additionally, ultrasound should not be used in patients with joint prostheses.

Keywords: Musculoskeletal injuries, cryotherapy, thermotherapy, complications used since antiquity for the treatment of musculoskeletal injuries, we only recently have developed an understanding of the complexity of their physiological actions. Current research has clarified their contraindications and identified an expanded role for their use in the treatment of many painful conditions, further broadening their indications.

\section{Pathophysiology of Pain}

In response to tissue injury, specialized nerve endings called nociceptors are activated. Nociceptors transmit nerve signals that travel through the spinal cord to the brain, where the sensation of pain is recognized. At the same time, neurotransmitters initiate a spinal reflex that increases muscle motor activity and tonicity at the site of injury, leading to a reflexive muscle contraction. If persistent, the increase in muscle tone can cause painful muscle spasms, which can lead to further tissue damage due to decreased blood flow and oxygen (hypoxia) to the surrounding tissues. Pain in turn increases. This injury process is called the pain-spasm-pain cycle (Fig. 1). This cycle must be interrupted to prevent further tissue injury and to reduce the sensation of pain.
Thermoreceptors, special temperature-sensitive nerve endings, are activated by changes in skin temperature. These receptors initiate nerve signals that block nociception (the pain signal processing that results from a noxious stimulus) within the spinal cord. Topical modalities applied with physical support activate another type of specialized nerve endings called proprioceptors. Proprioceptors detect physical changes in tissue pressure and movement. Proprioceptor activity also inhibits the transmission of nociceptive signals to the brain. The activation of these receptors within the spinal cord reduces muscle tone, relaxes painful muscles, and enhances tissue blood flow.

\section{CRYotherapy}

Cryotherapy is defined as the therapeutic application of any substance to the body that removes heat from the body, resulting in decreased tissue temperature. The pathophysiologic effects of cryotherapy are summarized in Table 1. Cryotherapy decreases tissue blood flow by causing vasoconstriction, and reduces tissue metabolism, oxygen utilization, inflammation, and muscle spasm. Common meth- 


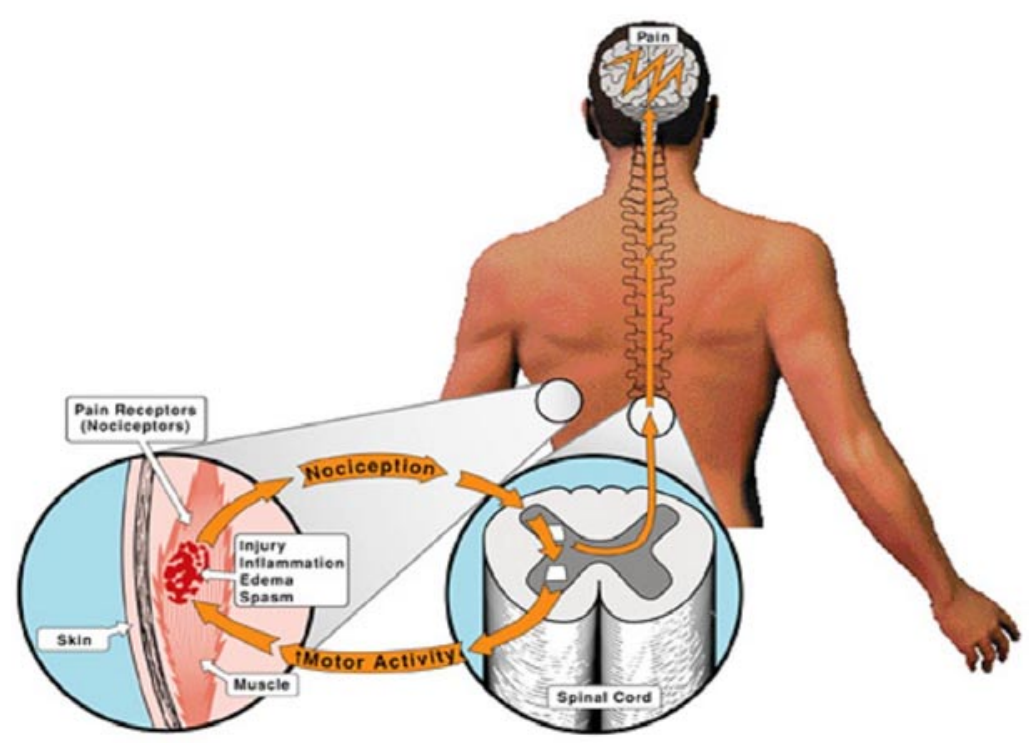

Fig 1. The pain-spasm-pain cycle

Table 1. Pathophysiologic effects of topical modalities

\begin{tabular}{|l|c|c|}
\hline & Cold & Heat \\
\hline Pain & & \\
\hline Spasm & & \\
\hline Metabolism & & \\
\hline Blood Flow & & \\
\hline Inflammation & & \\
\hline Edema & & \\
\hline Extensibility & & \\
\hline
\end{tabular}

ods of cold application and indications and contraindications for cryotherapy are listed in Table 2.

Cryotherapy induces effects both locally (at the site of application) and at the level of the spinal cord via neurologic and vascular mechanisms. Topical cold treatment decreases the temperature of the skin and underlying tissues to a depth of 2 to $4 \mathrm{~cm}$, decreasing the activation threshold of tissue nociceptors and the conduction velocity of pain nerve signals (2). This results in a local anesthetic effect called cold-induced neuropraxia.

Current research shows that cryotherapy decreases tissue blood flow and cell metabolism. A study (3) using bone scanning demonstrated that the application of an ice wrap to one knee for 20 minutes decreased arterial blood flow by $38 \%$; soft tissue blood flow by $26 \%$; and bone uptake, which reflects changes in bone blood flow and metabolism, by $19 \%$.
This study supports the use of ice for treating both soft tissue and bone after an acute traumatic injury to a large joint.

Continuous cryotherapy has been shown to have a protective effect on injured tissue. An animal study (4) showed that with primary injury to muscle, secondary hypoxic injury to the surrounding tissue was slowed with five hours of continuous cryotherapy. Slowing the rate of metabolism reduces the rate of oxygen consumption, subsequent tissue hypoxia, and additional tissue injury.

Two commonly held beliefs are that topical cold modalities are useful only for immediate care of acute injuries and are safe with only short duration of treatment. Current research, however, supports the use of topical cold in a variety of situations. Depending upon the method of application, cold modalities may have different physiologic effects. For example, one study (5) found that ice massage cools the muscle faster than an ice pack. In another study (6), both ice pack and cold whirlpool treatment for 20 minutes decreased calf muscle temperatures at the same rate. After 20 minutes, muscle tissue temperatures continued to decline for the whirlpool-treated group, but progressively increased in subjects treated with an ice pack. These results suggest that ice pack and ice message therapy are appropriate when a quick recovery is desired, such as an immediate "return to play," whereas cold whirlpool cryotherapy is most appropriate when long-term tissue cooling is needed.

One randomized study (7) found that both intermittent compression and continuous ice water treatment were more effective than intermittent cool pack therapy for foot and ankle injuries. After 24 hours of treatment, reduction of swelling was highest (47\%) in the group treated with intermittent compression, while the continuous ice water treatment provided a 33\% decrease in swelling. Conventional intermittent ice pack treatment reduced swelling by only $17 \%$. After four days' treatment, the intermittent compression and continuous ice water treatments were essentially equivalent with an approximately $70 \%$ reduction in swelling, compared with a $45 \%$ reduction with intermittent ice pack therapy. This study showed that continuous cold water treatment is preferable to cool packs for reduc- 
Table 2. Characteristics of hot and cold treatment modalities

\begin{tabular}{|c|c|c|c|c|}
\hline & Method of Application & Indications & Precautions & Adverse Treatment Effects \\
\hline Cryotherapy & $\begin{array}{l}\text { Ice pack } \\
\text { Vapo-coolant spray } \\
\text { Ice massage } \\
\text { Cold whirlpool }\end{array}$ & $\begin{array}{l}\text { Acute injury/trauma } \\
\text { Chronic pain } \\
\text { Muscle spasm } \\
\text { Delayed onset muscle } \\
\text { soreness } \\
\text { Inflammation }\end{array}$ & $\begin{array}{l}\text { Circulatory insufficiency } \\
\text { Cold allergy } \\
\text { Advanced diabetes }\end{array}$ & 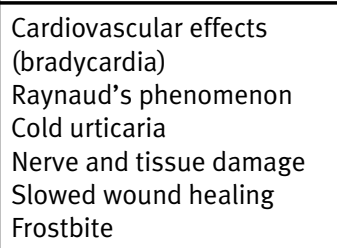 \\
\hline Thermotherapy & $\begin{array}{l}\text { Conduction } \\
\text { Hydrocollator pack } \\
\text { Low-level heat wrap } \\
\text { Paraffin bath }\end{array}$ & $\begin{array}{l}\text { Acute muscular pain } \\
\text { Delayed onset muscle } \\
\text { soreness } \\
\text { Menstrual pain }\end{array}$ & $\begin{array}{l}\text { Diabetes mellitus } \\
\text { Multiple sclerosis } \\
\text { Peripheral vascular } \\
\text { disease } \\
\text { Spinal cord injuries } \\
\text { Rheumatoid disease }\end{array}$ & Burns \\
\hline \multirow[t]{2}{*}{$\begin{array}{l}\text { Thermotherapy } \\
\text { (continued) }\end{array}$} & $\begin{array}{l}\text { Convection } \\
\text { Fluidotherapy } \\
\text { Hydrotherapy } \\
\end{array}$ & Wound debridement & & $\begin{array}{l}\text { Infections } \\
\text { Cardiovascular issues }\end{array}$ \\
\hline & $\begin{array}{l}\text { Conversion } \\
\text { Ultrasound } \\
\text { Heat lamp } \\
\text { Diathermy }\end{array}$ & $\begin{array}{l}\text { Tendonitis } \\
\text { Joint contractures } \\
\text { Muscle spasms } \\
\text { Osteoarthritis }\end{array}$ & $\begin{array}{l}\text { Pregnancy } \\
\text { Laminectomy sites } \\
\text { Spinal cord } \\
\text { Malignancy } \\
\text { Vascular insufficiency } \\
\text { Eye, testes, heart } \\
\text { Growth plates } \\
\text { Anesthetic area } \\
\text { Joint prosthesis } \\
\text { Total hip replacement }\end{array}$ & $\begin{array}{l}\text { Burns } \\
\text { Increased pain } \\
\text { Increased inflammation }\end{array}$ \\
\hline Contrast Therapy & $\begin{array}{l}\text { Alternating cryotherapy } \\
\text { and thermotherapy }\end{array}$ & $\begin{array}{l}\text { Complex reflex } \\
\text { sympathetic dystrophy } \\
\text { Desensitization of skin }\end{array}$ & & $\begin{array}{l}\text { Burns } \\
\text { Frostbite } \\
\text { Cold urticaria } \\
\text { Raynaud's phenomenon }\end{array}$ \\
\hline
\end{tabular}

ing posttraumatic edema.

\section{Complications of Cryotherapy}

Caution must be exercised when applying cryotherapy in the vicinity of superficial nerves, especially if cold is combined with compression. Peroneal neuropathy (8) as well as ulnar, axillary, and lateral femoral cutaneous nerve injury (9) after cryotherapy has been documented in the literature. Other reported side effects of cryotherapy include cardiovascular effects (bradycardia), Raynaud's phenomenon, cold urticaria, frostbite, and slowed wound healing secondary to decreased metabolic activity $(10,11)$.

\section{THERMOTHERAPY}

Thermotherapy is the therapeutic application of any substance to the body that adds heat to the body resulting in increased tissue temperature. Characteristics of various thermal modalities are listed in Table 2. Heat therapy, which can be either superficial or deep, is like cryotherapy in that it provides analgesia and decreased muscle tonicity. Unlike cryother- apy, thermotherapy increases tissue temperature, blood flow, metabolism, and connective tissue extensibility (Table 1). Heat therapy is delivered by three mechanisms: conduction, convection, or conversion.

Increased blood flow facilitates tissue healing by supplying protein, nutrients, and oxygen at the site of injury. A $1{ }^{\circ} \mathrm{C}$ increase in tissue temperature is associated with a $10 \%$ to $15 \%$ increase in local tissue metabolism (12). This increase in metabolism aids the healing process by increasing both catabolic and anabolic reactions needed to degrade and remove metabolic by-products of tissue damage and provides the milieu for tissue repair.

Some of the benefits provided by topical heat therapy may be mediated directly in the brain. Functional brain imaging research (13) has revealed central effects of non-noxious skin warming with increased activation of the thalamus and posterior insula of the brain. In addition, innocuous tactile stimulation of the skin activates the thalamus and S2 region of the cerebral cortex. These direct effects on the brain may mitigate the sensation of pain in the brain, thereby providing pain relief.

Topical heat treatment applied directly on the skin increases both deep tissue temperature and blood flow. Mulkern et al (14) found that heating pad treatment on the skin of the lower back region at $40^{\circ} \mathrm{C}$ increased deep muscle tissue temperature $5^{\circ} \mathrm{C}, 3.5^{\circ} \mathrm{C}$, and $2^{\circ} \mathrm{C}$ at muscle tissue depths of $19 \mathrm{~mm}, 28 \mathrm{~mm}$, and 38 $\mathrm{mm}$ below the surface of the skin, respectively. Conductive topical heat treatment of the knees of healthy subjects increased popliteal artery blood flow by $29 \%, 94 \%$, and $200 \%$ after 35 minutes of treatment with heating pad temperatures of $38^{\circ} \mathrm{C}$, $40^{\circ} \mathrm{C}$, and $43^{\circ} \mathrm{C}$, respectively (15). Erasala et al (16) demonstrated that deep tissue blood flow was found to increase $27 \%$, $77 \%$, and $144 \%$ in the trapezius muscle of healthy volunteers with heating pad treatments, resulting in skin temperature increases of $38^{\circ} \mathrm{C}, 40^{\circ} \mathrm{C}$, and $42^{\circ} \mathrm{C}$, respectively. The latter two studies show a twoto threefold increase in deep tissue blood flow with moderate levels of conductive 
topical heat treatment applied directly to the skin. In addition, it was recently reported that a significant increase in trapezius muscle conduction velocity, most likely due to increased tissue blood flow, occurred with hot pack treatment at moderate temperatures (17).

Although the differences between moist and dry heat are commonly referred to in clinical practice, scientific data supporting the alleged differences are lacking. This belief began with a 1946 study (18) that showed moist (hot baths) heat warms tissue faster than dry (infrared lamp) heat. Moisture increases the rate of heat energy transfer and tissue warming. Although these findings support the use of moist heat when rapid tissue warming is desired (such as during an office visit when time is limited), the results do not show that moist heat is therapeutically superior to dry heat. In fact, no therapeutic outcomes were measured during the study. Furthermore, dry heat (infrared lamp treatment) is rarely used anymore as a topical heat modality.

Continuous low-level heat therapy directly on the skin has been shown to be safe and therapeutically effective in treating musculoskeletal disorders. A randomized controlled clinical trial (19) evaluating the effects of a wearable medical device that provided eight hours of continuous low-level heat therapy for the treatment of delayed onset muscle soreness of the quadriceps muscles was reported. The results showed significant increases in pain relief after eight hours of heated knee wrap wear at temperatures of $38^{\circ} \mathrm{C}$ and $40^{\circ} \mathrm{C}$ compared with a control group that wore unheated control wraps on both knees.

Continuous low-level heat therapy directly on the skin has also been found to be effective for treating acute muscular low back pain and menstrual pain. Steiner et al (20) in a randomized controlled trial showed a significant increase in pain relief with continuous low-level heat therapy for eight hours per day over three consecutive days compared to an unheated control treatment. The significant increase in pain relief persisted in the heattreated group 24 hours after all treatments were stopped. Akin et al (21) demonstrated that continuous low-level heat therapy with a wearable medical device applied directly on the skin of the lower abdomen for 12 hours per day for two days, provided significant pain relief in patients with dysmenorrhea when compared to a control group wearing an unheated device. The pain relief was similar to that obtained with the maximum over-the-counter dose of oral ibuprofen.

Additionally, a recent prospective randomized study (22) showed that topical heat applied directly to the skin was superior to both acetaminophen and ibuprofen in the treatment of acute low back pain for all therapeutic measurements, including pain relief, muscle stiffness, lateral trunk flexibility, and disability. Pain relief was greater with the heat wrap than with either acetaminophen $(>52 \%)$ or ibuprofen $(>33 \%)$. Two days after treatment was discontinued, extended pain relief was significantly greater for the heat wrap than for either acetaminophen $(>34$ $\%)$ or ibuprofen $(>56 \%)$.

Continuous low-level heat therapy is also effective for the treatment of wrist pain associated with strains, sprains, and osteoarthritis. Michlovitz et al (23) showed incremental pain relief with eight continuous hours of topical heat treatment for three consecutive days compared with placebo treatment. Pain relief progressively increased with each successive day of therapy and persisted in the heat-treated group on the fourth and fifth day after all treatments were stopped. The therapeutic benefit of heat therapy in subjects with wrist pain included a significant increase in grip strength after three consecutive days of low-level heat therapy, which remained two days after all treatment had stopped. Similar therapeutic benefits were observed in subjects with carpal tunnel syndrome.

\section{Complications of Thermotherapy}

Thermotherapy should be used with caution in patients with diabetes mellitus, multiple sclerosis, poor circulation, spinal cord injuries, and rheumatoid arthritis because it may cause disease progression, burns, skin ulceration, and increased inflammation $(24,25)$. When using thermotherapy, skin should be protected in heatsensitive or high-risk patients, especially over regions with sensory deficits. Caution should be used with products generating high intensity heat (greater than $45^{\circ} \mathrm{C}$ ), such as with Hydrocollator packs or electric heating pads. Application time should be restricted for modalities that heat to high intensity levels. Infections of the skin (26), urinary tract (27), and pulmonary system (28) have been associated with whirlpool use.

Complications of ultrasound include altered cellular function, plasma membrane damage, acceleration of metabolic processes, and temporary stoppage of blood flow. Ultrasound is contraindicated over the eye, testes, heart, pregnant uterus, spinal cord injuries, laminectomy sites, anesthetic areas, malignancy, and growth plates, and in vascular insufficiency.

Additionally, ultrasound should not be used in patients with joint prostheses. Ultrasound therapy may cause overheating, cracking, and melting of the prosthetic joint due to a greater absorption of energy in the prosthesis than in overlying soft tissue (29). Loosening of cement in total hip replacement is the most common joint prosthesis effect with ultrasound therapy.

\section{Contrast Therapy}

Contrast therapy (treatment that alternates between cryotherapy and thermotherapy) is commonly used in rheumatic conditions and regional pain syndrome. Two well-controlled studies have shown that contrast therapy has no effect on muscle tissue temperature. The first (30) was conducted with whirlpool contrast treatments of healthy subjects over a 20-minute time period at a ratio of 4:1 minutes for heat and cold exposure of the lower leg, respectively. Calf muscle temperatures increased significantly in the heated control group, but no change in muscle temperature was detected in the contrast therapy group. Similar findings were reported in a second study (31) that involved alternating hot and cold pack treatments over a 20-minute period of time at a ratio of 1:1 (five-minute exposures). Calf muscle temperatures decreased significantly in the ice-treated control group. No significant changes in overall muscle temperature with contrast therapy were observed.

The therapeutic benefits of whirlpool contrast therapy in the biceps delayed-onset-muscle-soreness model were studied (32). Contrast, cold and heated whirlpool treatments were administered at $24,48,72$, and 96 hours after the inciting novel exercise. Contrast therapy decreased pain intensity at 72 and 96 hours after exercise compared with an untreated control group, but this response was similar to that observed with cold whirlpool therapy alone. Although the heated whirlpool therapy did not affect the in- 
tensity of pain in this study, the degree of resting elbow flexion was better with heated whirlpool therapy than with contrast therapy.

\section{ConCLUSION}

Therapeutic modalities are commonly used in the treatment of various musculoskeletal disorders. A thorough understanding of the physiologic effects of these modalities within the peripheral and central nervous system especially in regards to the pain-spasm-pain cycle is important for any clinician dealing with musculoskeletal pain. Newer research has demonstrated the superior effects of continuous cryotherapy and thermotherapy in the treatment of pain as opposed to intermittent treatment. Pain physicians need to be aware of current research into therapeutic modalities, which may be utilized by their patients in therapy and at home.

\section{Author Affiliation: \\ Scott F. Nadler, DO, FACSM \\ Director of Sports Medicine \\ New Jersey Medical School \\ 90 Bergen Street, Suite 3100 \\ Newark, New Jersey 07102 \\ E-mail: sfnadler@cs.com}

Kurt Weingand, PhD, DVM

Principal Clinical Scientist

P\&G Health Sciences Institute

One Procter \& Gamble Plaza

Cincinnati, Ohio 45202

\section{Roger J. Kruse, MD}

Medical Director, Sports Care

Head Physician, University of Toledo 28765 North Reynolds Road, Suite 130

Toledo, Ohio 43615

\section{References}

1. Praemer A, Furner S, Rice DP. In Musculoskeletal Conditions in the United States. 2nd ed., Rosemont, American Academy of Orthopaedic Surgeons, 1999, pp 83,104, 146.

2. Nadler SF, Weingand KW, Stitik TP et al. Pain relief runs hot and cold. BiomechaniCS 2001; 8:1.

3. Ho SS, Coel MN, Kajawa R et al. The effects of ice on blood flow and bone metabolism in knees. Am J Sports Med 1994; 22:537-540.

4. Merrick MA, Rankin JM, Andres FA et al. A preliminary examination of cryotherapy and secondary injury in skeletal muscle. Med Sci Sports Exerc 1999; 31:1516-1521.

5. Zemke JE, Andersen JC, Guion WK et al. Intramuscular temperature responses in the human leg to two forms of cryotherapy: ice message and ice bag. J Orthop Sports Phys Ther 1998; 27:301-307.

6. Myrer JW, Measom G, Fellingham GW. Temperature change in the human leg during and after two methods of cryotherapy. J Athletic Training 1998; 33:25.

7. Stockle U, Hoffmann R, Schutz $M$ et al. Fastest reduction of posttraumatic edema: continuous cryotherapy or intermittent impulse compression. Foot Ankle Int 1997; 18:432-438.

8. Moeller JL, Monroe J, McKeag DB. Cryotherapy-induced common peroneal nerve palsy. Clin J Sport Med 1997; 7:212-216.

9. Bassett FH, Kirkpatrick JS, Engelhardt DL et al. Cryotherapy-induced nerve injury. Am J Sport Med 1992; 20:516-518.

10. Saxena A. Achilles peritendinosis: An unusual case due to frostbite in an elite athlete. J Foot Ankle Surg 1994; 33:87-90.

11. Sallis R, Chassay CM. Recognizing and treating common cold-induced injury in outdoor sports. Med Sci Sport Exerc 1999; 31:1367-1373.

12. Cameron MH. Thermal agents: physical principles, cold and superficial heat. In Physical Agents in Rehabilitation: From Research to Practice. Philadelphia, Saunders, 1999, pp 149-175.

13. Davis KD, Kwan CL, Crawley AP et al. Func tional MRI study of thalamic and cortical activations evoked by cutaneous heat, cold, and tactile stimuli. J Neurophysiol 1998; 80:1533-1546.

14. Mulkern R, McDannold N, Hynynen K et al. Temperature distribution change in low back muscles during applied topical heat: A magnetic resonance thermometry study. Proc Int Soc Mag Res in Med, Philadelphia, May 22-28, 1999.

15. Reid RW, Foley JM, Prior BM et al. Mild topical heat increases popliteal blood flow as measured by MRI. Med Sci Sports Exer 1999; 31:S208.

16. Erasala GN, Rubin JM, Tuthill TA et al. The effect of topical heat treatment on trapezius muscle blood flow using power Doppler ultrasound. Physical Therapy 2001; 81:A5.

17. Nadler SF, DePrince ML, Stitik TP et al. Experimentally induced trapezius fatigue and the effects of topical heat on the EMG power density spectrum. Am J Phys Med Rehab 1999; 80:1123.
18. Martin GM, Roth GM, Elkins EC et al. Cutaneous temperature of the extremities of normal subjects and of patients with rheumatoid arthritis. Arch Phys Med 1946; 27:665.

19. Weingand KW, Hengehold D, Knight E et al. Topical heat provides pain relief of delayed muscle soreness of the distal quadriceps muscles. Med Sci Sports Exerc 1999; 31:S75.

20. Steiner D, Ersala G. Hengehold D et al. Continuous low-level heat therapy for acute muscular low back pain. In Proceedings of the 19th Annual Scientific Meeting of the American Pain Society 2000; 112.

21. Akin MD, Weingand KW, Hengehold DA et al. Continuous low-level topical heat in the treatment of dysmenorrhea. Obstet Gynecol 2001; 97:343-349.

22. Nadler SF, Steiner DJ, Erasala $G N$ et al. Continuous low level heat wrap therapy provides more efficacy than ibuprofen and acetaminophen for acute low back pain. Spine 2002; 27:1012-1014.

23. Michlovitz SL, Erasala GN, Hengehold DA et al. Continuous low-level heat therapy for wrist pain. Orthopedics 2002; 25:S1467.

24. Berger JR, Sheremata WA. Persistent neurological deficit precipitated by hot bath test in multiple sclerosis. JAMA 1983; 249: 1751-1753.

25. Harris ED, McCroskery PA. The influence of temperature and fibril stability on degradation of cartilage collagen by rheumatoid synovial collagenase. N Eng J Med 1974; 290:1-6.

26. Spitalny KC, Vogt RL, Witherell LE. National survey on outbreaks associated with whirlpool spas. Am J Public Health 1984; 74:725-726.

27. Salmen P, Dwyer DM, Vorse $\mathrm{H}$ et al. Whirlpool-associated Pseudomonas aeruginosa urinary tract infections. JAMA 1983; 250:2025-206.

28. Rose HD, Franson TR, Sheth NK et al. Pseudomonas pneumonia associated with use of a home whirlpool spa. JAMA 1983; 250: 2027-2029.

29. Lehmann JF, Warren CG, Wallace JE et al. Ultrasound: Considerations for use in the presence of prosthetic joints. Arch Phys Med Rehabil 1980; 61:502.

30. Myrer W, Draper DO, Durrant E. Whirlpool contrast therapy. J Athletic Training 1994; 29:318-322.

31. Myrer JW, Measom G, Durrant E et al. Coldand hot-pack contrast therapy: subcutaneous and intramuscular temperature change. J Athletic Training 1997; 32:238.

32. Kuliogowski LA, Lephart SM, Giannantonio FP. Whirlpool contrast therapy. J Athletic Training 1998; 33:222. 
